\title{
Streptococcus suis Infection in Hospitalized Patients, Nakhon Phanom Province, Thailand
}

\author{
Prabda Praphasiri, Jocelynn T. Owusu, Somsak Thammathitiwat, Darunee Ditsungnoen, \\ Pimpawan Boonmongkon, Ornuma Sangwichian, Kriengkrai Prasert, Sankhom Srihapanya, \\ Kanlaya Sornwong, Anusak Kerdsin, Surang Dejsirilert, Henry C. Baggett, Sonja J. Olsen
}

\begin{abstract}
In Nakhon Phanom, Thailand, we identified 38 hospitalized patients with Streptococcus suis infection during 2006-2012. Deafness developed in 12 patients; none died. Thirty-five reported recent exposure to pigs/pork. Annual incidence was $0.1-2.2$ cases $/ 100,000$ population $(0.2-3.2$ in persons $\geq 20$ years of age). Clinicians should consider $S$. suis infection in areas where pig exposure is common.
\end{abstract}

Streptococcus suis, a zoonotic pathogen found primar$\mathcal{N}$ ily in pigs, can cause serious infection in humans. Most cases in human occur in Southeast Asia, where pig rearing is common (1). In a recent global review, Thailand had the second highest number of reported cases, accounting for $11 \%$ of all reported cases worldwide (2). In Thailand, the first 2 cases of $S$. suis in humans were reported in 1987 (3). From 1997 (when S. suis infection was first reportable) through 2010, a total of 692 cases were reported (0-207 per year); nearly half were from northern Thailand (4). The national annual crude incidence rate was $0-0.381$ per 100,000 persons (Table 1). The objective of this study was to describe persons hospitalized with, and incidence of, S. suis infection in Nakhon Phanom during 2006-2012.

\section{The Study}

In 2003, the Thailand Ministry of Public Health and the US Centers for Disease Control and Prevention established hospital-based surveillance for community-acquired acute lower respiratory infections (ALRI) at all 12 acute-care hospitals in Nakhon Phanom Province (northeastern Thailand; population 761,623) (5). In 2005, surveillance was expanded to include bloodstream infections, supported by the addition of an automated blood culture system and improved

Author affiliations: Thailand Ministry of Public Health-US Centers for Disease Control and Prevention Collaboration, Nonthaburi, Thailand (P. Praphasiri, J.T. Owusu, S. Thammathitiwat, D. Ditsungnoen, O. Sangwichian, H.C. Baggett, S.J. Olsen); Mahidol University, Nakhon Pathom, Thailand (P. Praphasiri, P. Boonmongkon); Nakhon Phanom Provincial Health Office, Nakhon Phanom (K. Prasert, S. Srihapanya, K. Sornwong); Thailand Ministry of Public Health, Nonthaburi (A. Kerdsin, S. Dejsirilert); Centers for Disease Control and Prevention, Atlanta, Georgia, USA (H.C. Baggett, S.J. Olsen)

DOI: http://dx.doi.org/10.3201/eid2102.140961 microbiology capacity (6). Blood was collected for culture at clinician discretion but encouraged for all patients with ALRI and children $<5$ years of age who had sepsis. Incidence of pneumococcal bacteremia (all ages) and other bloodstream infections (children $<5$ years) was previously published $(6,7)$. This work was considered public health surveillance and thus exempt from institutional review board review.

Blood put into a blood culture bottle was transported at $15-30^{\circ} \mathrm{C}$ within 24 hours to the provincial hospital laboratory and processed by using the BacT/ALERT 3D automated blood culture system (bioMérieux, Durham, NC, USA). To obtain at least $10 \mathrm{~mL}$ per adult patient, we divided specimens into 2 bottles (standard aerobic growth and enhanced growth of fastidious pathogens). Bottles that indicated positive growth were subcultured and processed by standard methods (8). All possible pathogens were confirmed at the National Institute of Health, Ministry of Public Health, by conventional biochemical tests (9). We serotyped S. suis isolates using PCR (10) and confirmed serotypes by coagglutination using rabbit antiserum (Statens Serum Institut, Copenhagen, Denmark). A case of $S$. suis was defined as illness in a person hospitalized in Nakhon Phanom who had blood culture-confirmed S. suis infection. Two physicians (K.P. and S.S.) reviewed the medical data retrospectively. Patients were interviewed by using a standard protocol (http://www.boe.moph.go.th/files/ report/20100902_39823811.pdf). We calculated annual incidence using the estimated population as the denominator (http://www.nesdb.go.th/temp_social/pop.zip).

During 2006-2012, there were 56,983 blood cultures from 56,057 patients, an average of 8,008 patients per year (for comparison, in 2005, before microbiology enhancements, 2,340 patients had blood cultured at the provincial hospital). Median age of patients was 44 years (range $23-73$ years). A pathogen was identified in 4,097 (7.2\%) patients and S. suis in $38(0.07 \%)$. Of the 38 S. suis cases, two occurred in 2006 , one in 2007 , two in 2008 , three in 2009, eight in 2010, five in 2011, and 17 in 2012. Fiftyfive percent of cases were identified during April-June (Figure). The annual crude incidence ranged from 0.1 to 2.2 cases per 100,000 population; incidence was highest in 2012 (Table 1). Of persons $\geq 20$ years of age (all 38 S. suis patients), incidence was highest in 2012 (3.2 cases/100,000 population [range $0.2-3.2 / 100,000]$ ). 
Table 1. Incidence of Streptococcus suis, Nakhon Phanom Province, Thailand, 2006-2012

\begin{tabular}{|c|c|c|c|c|c|c|}
\hline \multirow[b]{3}{*}{ Year } & \multicolumn{3}{|c|}{ Nakhon Phanom } & \multicolumn{3}{|c|}{ Thailand } \\
\hline & \multirow[b]{2}{*}{ Population, all ages } & \multicolumn{2}{|c|}{ Active surveillance } & \multirow[b]{2}{*}{ Population, all ages $\dagger$} & \multicolumn{2}{|c|}{ Passive surveillance } \\
\hline & & No. cases & Crude incidence $^{*}$ & & No. cases & Crude incidence $^{*}$ \\
\hline 1997 & & & & $55,747,667$ & 1 & 0.002 \\
\hline 1998 & & & & $55,747,667$ & 0 & 0.000 \\
\hline 1999 & & & & $55,747,667$ & 1 & 0.002 \\
\hline 2000 & & & & $55,747,667$ & 1 & 0.002 \\
\hline 2001 & & & & $56,305,980$ & 3 & 0.005 \\
\hline 2002 & & & & $56,840,337$ & 1 & 0.002 \\
\hline 2003 & & & & $57,345,943$ & 1 & 0.002 \\
\hline 2004 & & & & $57,830,569$ & 1 & 0.002 \\
\hline 2005 & & & & $58,319,021$ & 10 & 0.017 \\
\hline 2006 & 734,000 & 2 & 0.27 & $58,755,907$ & 41 & 0.070 \\
\hline 2007 & 738,184 & 1 & 0.14 & $59,199,510$ & 90 & 0.152 \\
\hline 2008 & 742,500 & 2 & 0.27 & $59,626,014$ & 106 & 0.178 \\
\hline 2009 & 746,655 & 3 & 0.40 & $60,037,264$ & 229 & 0.381 \\
\hline 2010 & 751,251 & 8 & 1.06 & $60,435,937$ & 207 & 0.343 \\
\hline 2011 & 754,931 & 5 & 0.66 & & & \\
\hline 2012 & 758,388 & 17 & 2.24 & & & \\
\hline
\end{tabular}

Within 24 hours after hospital admission, all patients were treated with ceftriaxone. In $12(32 \%)$ patients, permanant deafness developed; all had reported hearing loss at admission. Thirty-five (92\%) patients had exposure to pigs or pork in the 7 days before illness onset: $10(26 \%)$, all women, reported preparing pork with their bare hands for consumption and eating undercooked pork, 12 (32\%) reported eating both undercooked/uncooked pork and clotted pig blood, and 13 (34\%) reported slaughtering pigs for their own consumption. Thirteen patients who reported slaughtering pigs also ate pork but stated that they could not recall how the meat was prepared because of having also consumed alcohol. Seven $(18 \%)$ patients had acquired pigs in poor health from commercial farms at reduced prices or no cost. Patients resided in $18(19 \%)$ of the 96 subdistricts within Nakhon Phanom, and 10 (26\%) patients resided in the same subdistrict. Two clusters of cases occurred in 2012, in which 2 and 3 persons ate raw pork and drank alcohol together. All patients reported no prior knowledge of $S$. suis infection, its symptoms, or ways to prevent infection.

Of the 24 patients with meningitis, $21(88 \%)$ had leukocytosis, 4 (17\%) had thrombocytopenia, and $2(8 \%)$ had thrombocytosis. Six of the 24 patients with meningitis had a

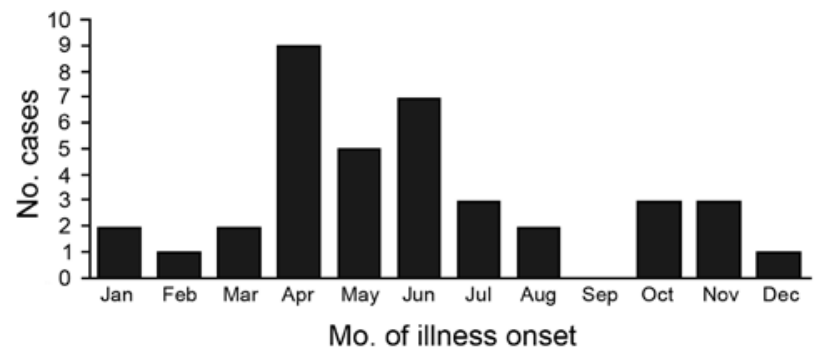

Figure. Cases of Streptococcus suis infection, by month of illness onset, Nakhon Phanom Province, Thailand, 2006-2012. cerebrospinal fluid (CSF) culture; 1 was positive for S. suis. Of the 10 patients with septicemia, 5 had leukocytosis, 1 had leukopenia, 3 had normal leukocyte counts; for 1, leukocyte count was unavailable. Thirty (79\%) isolates were initially reported as Streptococcus group D nonenterococci by the hospital laboratory; the remaining 8 were reported as other streptococcal groups or species (Table 2). The National Institute of Health reference laboratory identified $S$. suis in 38 patients; all isolates were serotype 2 (PCR and coagglutination results were all concordant). All isolates tested for antimicrobial resistance by disk diffusion (KirbyBauer) were susceptible to penicillin (37 isolates) and ceftriaxone (11 isolates). Time from patient blood collection to final pathogen report to the clinician was 30-45 days.

\section{Conclusions}

S. suis infection is common in northern Thailand. Here we report laboratory-confirmed cases and incidence in Nakhon Phanom, a northeastern province. Few other studies have reported incidence. The Netherlands reported the most $S$. suis infections in the West (2) with an estimated annual incidence of $S$. suis infection of 0.002 cases per 100,000 persons (11), and the incidence in northern Thailand was 6.2 cases per 100,000 persons (12). Active surveillance suggests that $S$. suis infection might be more common in this region than previously realized (e.g., in 2010, the incidence in Nakhon Phanom was 1.6-fold higher in active than passive reporting; for other years it was greater). During 2006-2012, a total of 45\% (17/38) of S. suis infection were detected in 2012, including 2 clusters.

Although we did not have a control group with which to compare exposures, our findings are consistent with studies performed in northern Thailand that highlight pork/ pig exposure, combined with alcohol use, as a risk factor 
Table 2. Characteristics of 38 patients for whom blood culture confirmed Streptococcus suis infection, Nakhon Phanom Province, Thailand, 2006-2012

\begin{tabular}{|c|c|}
\hline Characteristic & Result of analysis or culture \\
\hline Male sex, no. (\%) & $28(74)$ \\
\hline Median age, y (range) & $50(23-73)$ \\
\hline Heavy alcohol use, no. $(\%)^{\star}$ & $20(53)$ \\
\hline Current smoker, i.e., smoked daily, no. (\%) & $21(55)$ \\
\hline Underlying chronic disease, no. (\%) & $12(32)$ \\
\hline Hypertension & $4(33)$ \\
\hline Diabetes & $3(25)$ \\
\hline Alcoholism† & $3(25)$ \\
\hline Heart disease & $1(0.8)$ \\
\hline Gout & $1(0.8)$ \\
\hline Occupation: farmer, no. (\%)‡ & $33(87)$ \\
\hline Consumption of/contact with pig or pork product, no. (\%) & $35(92)$ \\
\hline Days from pork/prok contact to illness onset, median (range) & $2(1-7)$ \\
\hline Days from illness onset to hospital admission, median (range) & $2(0-5)$ \\
\hline \multicolumn{2}{|l|}{ Clinical features } \\
\hline Meningitis, no. (\%) & $24(63)$ \\
\hline Septicemia, no. (\%) & $10(26)$ \\
\hline Arthritis, no. (\%) & $4(11)$ \\
\hline \multicolumn{2}{|l|}{ Laboratory investigation } \\
\hline \multicolumn{2}{|l|}{ Complete blood count, $n=37$} \\
\hline Leukocytosis, $>10,000$ cells $/ \mu \mathrm{L}$, no. (\%) & $28(76)$ \\
\hline Leukopenia, $<5,000$ cells $/ \mu \mathrm{L}$, no. (\%) & $1(3)$ \\
\hline Thrombocytosis, $>450,000$ cells/ $\mu \mathrm{L}$, no. $(\%)$ & $2(5)$ \\
\hline Thrombocytopenia, $<150,000$ cells/ $\mu \mathrm{L}$, no. (\%) & $7(19)$ \\
\hline \multicolumn{2}{|l|}{ CSF examination, $\S n=12$} \\
\hline Protein, mean $\pm \mathrm{SD}, \%$ & $580 \pm 421$ \\
\hline Glucose, mean $\pm \mathrm{SD}, \mathrm{mg} / \mu \mathrm{L}$ & $23 \pm 19$ \\
\hline Leukocyte count, mean $\pm S D$, cells $/ \mu \mathrm{L}$ & $2,210 \pm 1,580$ \\
\hline Polymorphonuclear neutrophils, mean $\pm \mathrm{SD}, \%$ & $54 \pm 28$ \\
\hline \multicolumn{2}{|l|}{ Blood culture result reported by hospital laboratory } \\
\hline Streptococcus group D, non-enterococci, no. (\%) & $30(79)$ \\
\hline Streptococcus group D, no. (\%) & $2(5)$ \\
\hline Streptococcus pyogenes, no. (\%) & $1(3)$ \\
\hline Group A $\beta$-hemolytic Streptococcus, no. (\%) & $1(3)$ \\
\hline$\beta$-Hemolytic Streptococcus, no. (\%) & $1(3)$ \\
\hline Streptococcus not group A,B,D, no. (\%) & $1(3)$ \\
\hline Enterococcus spp., no. (\%) & $1(3)$ \\
\hline Streptococcus spp., no. (\%) & $1(3)$ \\
\hline \multicolumn{2}{|l|}{ CSF culture results reported by hospital laboratory, $n=6$} \\
\hline Streptococcus group D, nonenterococci, no. (\%) & $5(83)$ \\
\hline Streptococcus suis, no. $(\%)$ & $1(17)$ \\
\hline Days hospitalized, median (range)\# & $7(3-19)$ \\
\hline Death, no. $(\%)$ & 0 \\
\hline Permanent deafness, no. $(\%)^{\star *}$ & $12(32)$ \\
\hline \multicolumn{2}{|c|}{$\begin{array}{l}\text { *Defined as self-reported drinking of }>2 \text { alcoholic beverages/day or }>14 \text { drinks/week for men and }>1 \text { alcoholic beverage/day or }>7 \text { drinks } / \text { week for } w \\
\text { †In } 1 \text {, cirrhosis also was diagnosed. } \\
\text { †Three raised livestock, and } 30 \text { harvested crops (rice). } \\
\text { \$Reference values: protein, } 15-45 \mathrm{mg} / \mu \mathrm{L} \text {; glucose, } 50-80 \mathrm{mg} / \mu \mathrm{L} \text {; leukocytes, } 0-5 \text { cells } / \mu \mathrm{L} \text {; polymorphonuclear neutrophils, } 0 \% \text {. } \\
\text { TAll } 38 \text { blood culture results were confirmed to be S. suis. } \\
\text { \#Excludes } 2 \text { patients who experienced septic shock and were transferred to the regional hospital (in another province) on the first day of admission. } \\
\text { **Ten patients had bilateral deafness, of whom } 2 \text { with deafness reported chronic ataxia; all } 12 \text { had meningitis. }\end{array}$} \\
\hline
\end{tabular}

(13). Unlike in cases reported in other studies (12), no patients reported here died. Patients were treated promptly with ceftriaxone on the first day of admission, which is standard empiric management of suspected sepsis or meningitis in these hospitals. Permanent hearing loss was common, and deafness is usually permanent when it occurs before treatment (14).

Our data have several limitations. Blood cultures were performed at clinician discretion and not necessarily for all patients with possible sepsis or meningitis, possibly resulting in missed cases or biasing our study toward the more clinically apparent or severe cases. Blood volume might have been too low for adequate pathogen yield. Only 6 patients had CSF cultures, and most blood and CSF cultures occurred after start of antimicrobial therapy. Therefore, meningitis patients with negative blood cultures might have been missed. Furthermore, because comprehensive examinations were not performed on patients after discharge, neurologic or cognitivie sequalae might have been missed.

Because most hospital laboratories in Thailand are not able to confirm $S$. suis, the infection might be misdiagnosed (14). Clinicians in high-risk areas, or who see patients with 
recent travel to high-risk areas, should have a low index of suspicion for $S$. suis infection among patients presenting with meningitis or sepsis and recent pig/pork exposure (15). Improving the capacity of local laboratories to identify $S$. suis will aid clinical management and facilitate outbreak detection and response. Rapid identification enables faster epidemiologic investigation and swift initiation of control measures (2).

\section{Acknowledgments}

We thank Anek Keawpan and Sopida Pookkit for their contributions to this project.

The US Centers for Disease Control and Preventon, the Ministry of Public Health, Thailand, and the Association of Schools and Programs of Public Health (cooperative agreements 5U19GH000004 and U36/CCU300430) provided funding for this study.

Dr. Prapasiri is an epidemiologist in the Influenza Program at the Thailand Ministry of Public Health-US Centers for Disease Control and Prevention Collaboration. His research interests include the epidemiology of acute respiratory illness and sociocultural risk factors for infectious diseases.

\section{References}

1. Wertheim HF, Nghia HD, Taylor W, Schultsz C. Streptococcus suis: an emerging human pathogen. Clin Infect Dis. 2009;48:617-25. http://dx.doi.org/10.1086/596763

2. Lun ZR, Wang QP, Chen XG, Li AX, Zhu XQ. Streptococcus suis: an emerging zoonotic pathogen. Lancet Infect Dis. 2007;7:201-9. http://dx.doi.org/10.1016/S1473-3099(07)70001-4

3. Phuapradit P, Boongird P, Boonyakarnkul S, Niramarnsakul S, Ponglikitmongkol S, Vorachit M, et al. Meningitis caused by Streptococcus suis. Intern Med. 1987;3:120-2.

4. Thailand Ministry of Public Health Bureau of Epidemiology. Laboratory surveillance of Streptococcus suis. 2013 [cited 2013 Sep 27]. http://www.boe.moph.go.th/Annual/aesr2553/AESR53 Part1/B_Part1_53/2553_StreptococcusLab.pdf

5. Olsen SJ, Thamthitiwat $\bar{S}$, Chantra S, Chittaganpitch M, Fry $\mathrm{AM}$, Simmerman JM, et al. Incidence of respiratory pathogens in persons hospitalized with pneumonia in two provinces in Thailand. Epidemiol Infect. 2010;138:1811-22. http://dx.doi.org/10.1017/ S0950268810000646

6. Baggett HC, Peruski LF, Olsen SJ, Thamthitiwat S, Rhodes J, Dejsirilert $\mathrm{S}$, et al. Incidence of pneumococcal bacteremia requiring hospitalization in rural Thailand. Clin Infect Dis. 2009;48 (Suppl 2):S65-74. http://dx.doi.org/10.1086/596484

7. Hasan R, Rhodes J, Thamthitiwat S, Olsen SJ, Prapasiri P, Naorat $\mathrm{S}$, et al. Incidence and etiology of acute lower respiratory tract infections in hospitalized children younger than 5 years in rural Thailand. Pediatr Infect Dis J. 2014;33:e45-52. http://dx.doi.org/10.1097/INF.0000000000000062

8. Perilla MJ, Ajello G, Bopp C, Elliott J, Facklam R, Knapp JS, et al. Manual for the laboratory identification and antimicrobial susceptibility testing of bacterial pathogens of public health importance in the developing world. Geneva: World Health Organization; 2003.

9. Facklam R. What happened to the streptococci: overview of taxonomic and nomenclature changes. Clin Microbiol Rev. 2002;15:613-30. http://dx.doi.org/10.1128/CMR.15.4.613-630.2002

10. Kerdsin A, Akeda Y, Hatrongjit R, Detchawna U, Sekizaki T, Hamada S, et al. Streptococcus suis serotyping by a new multiplex PCR. J Med Microbiol. 2014;63:824-30. http://dx.doi.org/10.1099/ jmm.0.069757-0

11. Arends JP, Zanen HC. Menigitis caused by Streptococcus suis in humans. Rev Infect Dis. 1988;10:131-7. http://dx.doi.org/10.1093/ clinids/10.1.131

12. Fongcom A, Pruksakorn S, Netsirisawan P, Pongprasert R, Onsibud P. Streptococcus suis infection: a prospective study in northern Thailand. Southeast Asian J Trop Med Public Health. 2009;40:511-7.

13. Khadthasima N, Sutdan D, Noimoh T, Chalamat M,

Thannawitjaya P, Areechoechai D, et al. Outbreak investigation of Streptococcus suis in Phusang district, Payao Province, May 2007. Wkly Epidemiol Surveill Rep. 2007;38:393-8 [cited 2013 Sep 27]. http://203.157.15.4/wesr/file/y50/F50231.pdf

14. Donsakul K, Dejthevaporn C, Witoonpanich R. Streptococcus suis infection: clinical features and diagnostic pitfalls. Southeast Asian J Trop Med Public Health. 2003;34:154-8.

15. Teekakirikul P, Wiwanitkit V. Streptococcus suis infection: overview of case reports in Thailand. Southeast Asian J Trop Med Public Health. 2003;34(Suppl 2):178-83.

Address for correspence: Prabda Praphasiri, Thailand MOPH-US CDC Collaboration, DDC Bldg 7, 4th Fl, Ministry of Public Health, Soi 4, Tivanon Rd, Nonthaburi 11000, Thailand; email: hpu3@cdc.gov

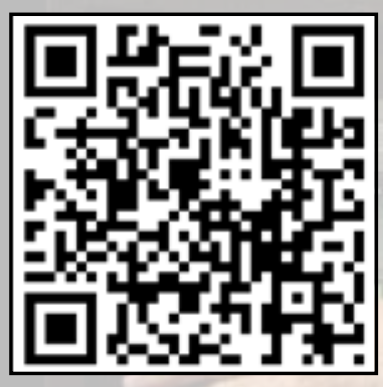

Scan this QR Code with your smartphone and enjoy listening to our podcasts about the latest emerging infectious diseases.

http://wwwnc.cdc.gov/eid/podcasts.htm

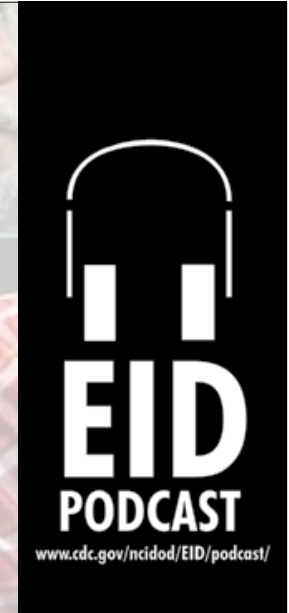

